\title{
Enteritis with immune checkpoint inhibitor use
}

\author{
David Sanders MD, Douglas Webber MD, Nazira Chatur MD
}

Cite as: CMAJ 2019 October 7;191:E1106. doi: 10.1503/cmaj.190244
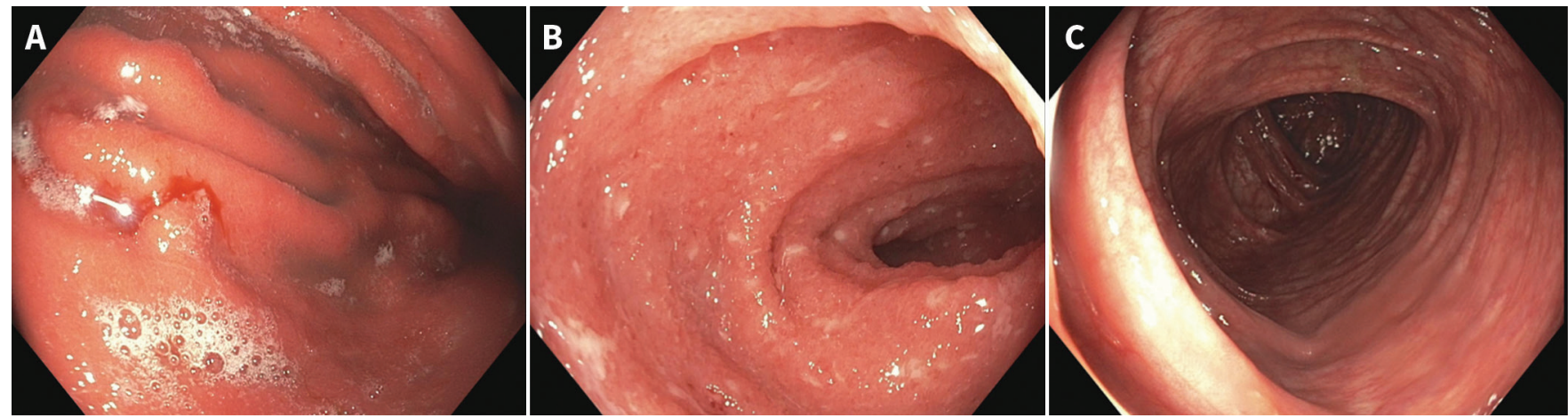

Figure 1: Esophagogastroduodenoscopy images of A) gastritis with nodularity, erythema and spontaneous oozing, and B) terminal ileitis with punctate apthous ulcerations and blunting of villi in a 43-year-old man with local recurrence of melanoma and metastatic disease. C) No endoscopic evidence of colitis.

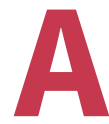
43-year-old man had a completely excised melanoma with local wide excision and negative sentinel node biopsy. Local recurrence and metastatic disease (confirmed by positron emission tomography) developed in his axillary lymph nodes, liver, bone and an adrenal gland. He was started on ipilimumab and nivolumab (immune checkpoint inhibitors) by his oncologist. He presented to his oncologist about 2 weeks later with nausea, vomiting, diarrhea and weight loss. He was having up to 10 episodes per day of nonbloody diarrhea and was admitted to hospital with dehydration despite oral prednisone. He was started on methylprednisolone administered intravenously; all results were negative for cultures of his stool, examination for ova and parasites, and the presence of Clostridioides difficile.

We performed an esophagogastroduodenoscopy that showed gastric (Figure 1A; Appendix 1, available at www.cmaj.ca/lookup/suppl/ doi:10.1503/cmaj.190244/-/DC1) and duodenal inflammation. A colonoscopy showed active terminal ileitis without colitis (Figures $1 \mathrm{~B}$ and $1 \mathrm{C}$, Appendix 1). These findings were consistent with grade 3 toxicity. ${ }^{1}$ The patient's symptoms did not respond at 72 hours to more than $2 \mathrm{mg} / \mathrm{kg}$ of intravenous methylprednisolone. We ruled out latent tuberculosis and chronic hepatitis $B$ virus infection before starting infliximab $(5 \mathrm{mg} / \mathrm{kg})$ in hospital. The diarrhea stopped after 1 dose, along with resolution of symptoms related to immune-mediated hepatitis and arthritis. Treatment with corticosteroids was eventually tapered off, and his symptoms completely resolved after 2 subsequent doses of infliximab.

Ipilimumab is an anticytotoxic T-lymphocyte-associated antigen-4 (CTLA-4) antibody and nivolumab is a programmed cell death protein 1 (PD-1) antibody that impedes the inhibitory signalling from cancer cells to cytotoxic T cells to prevent immunoevasion. ${ }^{1,2}$ Cytotoxic T-lymphocyte-associated antigen-4 is an important receptor for regulatory $\mathrm{T}$ cells. Corticosteroids promote regulator $\mathrm{T}$-cell activities and inhibit effector T-cell activities. In our patient, infliximab, an antitumour necrosis factor, was more effective than corticosteroids in halting immune-mediated gastroenteritis. ${ }^{3}$ The most common gastrointestinal immune-related toxicities with dual immune checkpoint inhibitor therapies include diarrhea (44\%), hepatitis (18\%) and colitis (12\%); however, gastritis, ${ }^{4}$ enteritis and pancreatitis can also occur.

The differential diagnosis of checkpoint inhibitor enteritis includes cytomegalovirus, other infectious enteritides, lymphocytic enteritis, drug-induced enteropathy, inflammatory bowel disease and graftversus-host disease. ${ }^{5}$

\section{References}

1. Brahmer JR, Lacchetti C, Schneider BJ, et al.; National Comprehensive Cancer Network. Management of immune-related adverse events in patients treated with immune checkpoint inhibitor therapy: American Society of Clinical Oncology clinical practice guideline. J Clin Oncol 2018;36:1714-68.

2. Esfahani K, Meti N, Miller WH Jr, et al. Adverse events associated with immune checkpoint inhibitor treatment for cancer. CMAJ 2019;191:E40-6.

3. Soularue E, Lepage P, Colombel JF, et al. Enterocolitis due to immune checkpoint inhibitors: a systematic review. Gut 2018;67:2056-67.

4. Yip RHL, Lee LH, Schaeffer DF, et al. Lymphocytic gastritis induced by pembrolizumab in a patient with metastatic melanoma. Melanoma Res 2018;28:645-7.

5. Karamchandani DM, Chetty R. Immune checkpoint inhibitor-induced gastrointestinal and hepatic injury: pathologists' perspective. J Clin Pathol 2018;71:665-71.

Competing interests: Nazira Chatur has received honoraria for presentations on immune checkpoint inhibitor-related colitis from Merck and Bristol-Myers Squibb. No other competing interests were declared.

This article has been peer reviewed.

The authors have obtained patient consent.

Affiliations: Division of Gastroenterology (Chatur), Department of Medicine, and Department of Pathology and Laboratory Medicine (Webber), Faculty of Medicine, Vancouver General Hospital (Sanders), University of British Columbia, Vancouver, BC

Correspondence to: David Sanders, david.sanders@alumni.ubc.ca 